\title{
5. Hit or myth? Stories of collaborative success ${ }^{1}$
}

\section{Chris Huxham and Paul Hibbert}

Partnering is notoriously difficult; success rates as low as 20 per cent are often quoted. So, is success achievable or are the benefits to be gained from partnering just a myth?

What does 'success' mean in partnerships, alliances and other collaborative ventures? The answer might not be as straightforward as you expect. We talked to partnership managers and their colleagues about the collaborations that they were pleased with. Naturally, they were concerned to tell us that they had achieved the objectives that they and their partners had jointly agreed to pursue. Their stories also told of other types of achievement; we identified five main categories of these. All seem to be important and need to be recognised as elements of positive collaborative progress.

We also found, however, that success was always qualified. Getting some sort of positive outcome was never completely straightforward. We think it is essential that people have a realistic idea of the costs and compromises necessary when seeking success in partnerships, so these caveats need to be recognised, too. Let us start, however, with the positive and review the five categories of achievement that we found in stories of success.

\section{Five types of collaborative success}

\section{Achieving outcomes}

People often point to particular outcomes for their shareholders, customers, clients or other stakeholders, but these can be outcomes of radically different types.

'Everyone was gaining from it all the way along. Pounds, shillings and pence on the bottom line.'

Banking Partnership Manager

'We have a robust ante-natal screening program and none of the babies (to HIV positive mothers) have proved positive.'

Drug Abuse Project Manager

The important lesson we draw from this is that outcome success in partnership can be characterised in a number of very different ways. This is a particularly 
important consideration in cross-sectoral partnerships, in which different notions of success might be at odds with each other. For example, what some people might see as a successful social project, others might consider a revenue drain. There is a need to see the situation from all sides, and temper our expectations.

\section{Getting the processes to work}

People don't just value the 'end result'; they are proud of getting the processes right, too. The 'how' seems to matter at least as much as the 'what'.

'A significant success on the organisational side and inter-organisational process side was that 10 pharmaceutical companies, who were natural competitors, learnt to work with each other.'

Health Industry Partnership Manager

We were given many examples of process success, and these could be things that worked at the individual as well as the organisational or inter-organisational levels. Clearly, processes are important to partnerships at all of these levels, and capturing the learning from process successes could be helpful in the future. The first step is to take the time to look for, and recognise, them.

\section{Reaching emergent milestones}

Good project planning in partnership - setting plans and milestones - is standard practice for many. Emergent milestones are, however, different. These are not events planned from the start, but semi-serendipitous achievements as particular circumstances come together in a helpful way. They are signals that the partnership has really achieved something, however great or small, and they are important indicators of success for many.

'... they both needed new premises. The cost was monstrous. So they decided.'

Banking Partnership Manager'

'It was quite a landmark ... getting such a public statement published and properly printed and distributed.'

Public Health Partnership Manager'

These emergent milestones can be the outcomes of large or small initiatives but even relatively small achievements can be important to participants - especially if they mark points at which 'hostilities cease' and the partnership starts to work effectively. 


\section{Gaining recognition - from others}

People seem to value partnership processes that work and outcomes that make a difference to the people they are serving not simply as ends in themselves. Often, they or their organisations receive something that they value just as much: recognition.

'We have been able to show a major client that we are able to operate as mature and sensible partners when they might perhaps suspected that wasn't the case.'

Manager in an Oil Industry Joint Venture

'I don't get treated like shit anymore ...'

Drug Abuse Project Manager'

Personal recognition seems to be the type of recognition that people mention most often, but they do like to see their organisations recognised too. Both of these seem quite legitimate aspirations, so perhaps the lesson is to not lose the people under the umbrella of the partnership.

\section{Acknowledging personal pride in championing a partnership}

As we have mentioned, people do seek recognition and therefore, perhaps understandably, they are often not shy about highlighting their role in 'making things happen'.

'Part of the reason I was successful was that I spent lots time getting to understand other parts of the business.'

Airline - Car-Rental Alliance Manager

'I willed it to happen and put an awful lot time in ... Health had initially been very suspicious of the partnership.'

Health Industry Partnership Manager

To be motivated, people have to be able to identify with the success that is achieved and see it as their own. Reaching the point at which individuals are willing to acknowledge overtly - and even promote - their own role in a partnership is therefore significant. If people portray themselves as heroes in a collaboration story, it is a sure indicator of some of the other four types of success, as well as being a positive outcome in itself.

It seems, from our research, that you are most likely to hear about collaborative successes from project 'champions'. What is interesting about them is that they do not generally display or behave as some sort of 'transformational leader'. It is difficult to suggest a common set of behaviours for champions, but stubborn 
determination seems to be important in most cases, often balanced with a concern for relationships.

'I was always having an uphill struggle to get people to push the things I wanted to get pushed.'

$$
\text { Airline - Car-Rental Alliance Manager }
$$

'It became apparent within two or three years that we had a family ... we worked, played and got drunk together.'

European Regional Partnership Manager

\section{But it's never straightforward...}

Stubborn determination seems to be central in achieving some success from partnerships and collaborations - for a very good reason. Even in the stories of success that we heard, there were four kinds of clear indication that it wasn't easy to get to the good stuff. As in most good stories, there are always challenges and setbacks that the heroes must overcome.

\section{It's usually an epic tale-definitely not a short story...}

For many, partnership seems to be intrinsically more difficult than other organisational situations. Even informal, emergent milestones take time to achieve.

People commonly talk about taking two years or more to get a partnership functioning well. Many people, however, who champion partnerships treat collaboration as their 'day job', so for them this is 'situation normal'.

\section{There's always a twist in the tale...}

Although a partnership has been successful - or at least functioning - for a prolonged period, that is no guarantee that it will remain so. In most cases, the good times come and go, and what works well at one time might not achieve results at another.

'Some times are better than others - for example, we had two attempts at building the joint site.'

Banking Partnership Manager

It would be easy to become complacent in the good times, but that would obviously be unwise.

\section{It's rarely a happy ending for all the characters...}

Even when a partnership seems to be robustly successful for one partner, it's possible that others might disagree. 


\section{Three Participants in a Youth Development Partnership}

'a really good forum for bringing services together ... It works - there are clear outcomes.'

Youth Development Worker

'a forum around a few individuals - don't feel it's working that well ... the housing department shift the goalposts to suit themselves.'

Charity Worker

'at one time we used to be able to be able to refer kids (to the charity) but we can't now because of their lack of resources.'

Housing Manager

It is impossible to judge, in such cases, whether the success is or is not 'real'. While there can be clear substantive outcomes for one partner (and the first speaker in Figure 5.8 describes some), other partners might view the outcomes as sub-optimal, as achievable by other means or of no value to their organisation.

\section{The genie is apt to stay in the bottle...}

Our fourth and final caveat, which emphasises the risky nature of collaboration, is that luck seems to play a part in most successful partnerships.

'My organisation was also involved in a similar - on paper - partnership with a transport company but [it wasn't successful in that case because] the client was less committed to the partnership philosophy than the traditional contracting philosophy.'

Manager in a Utilities Partnership

The stories we were told included many examples in which the speaker's organisation was involved in other partnerships that were not as successful as the one being described. Often a critical part of success seems to involve being in the right place at the right time, or having the right set of characters involved. Being able to tempt the genie out of his - or her-bottle to charm those circumstances into place is a significant part of the art of managing collaboration. We think of this as 'enhancing serendipity'.

\section{Is successful collaboration just a myth?}

The answer to this question is no! The collaborations we heard about were definitely hits. They were success stories for at least some-and probably many - of the participants. They were, however, stories told with hindsight and at a moment in a partnership's life when success was tangible. When you are in 
the thick of normal partnership life the story is likely to involve a lot of suspense and it might not be clear whether the plot involves a happy ending.

In those situations, it can be useful to think about the five types of success. They can be useful landmarks, ways to acknowledge the progress that is being made. Remembering that progress might not be on a single dimension is important, as well as the fact that partners can find different things to celebrate in each dimension. The 'five types' can form a useful basis for discussion between partners about past and future progress. They can also be useful in demonstrating value to external stakeholders.

\section{How to seek successful partnership}

First, take courage! The newcomer to partnership working can find their optimism quickly eroded, and 'battle-scarred' wisdom can drift over into calculating cynicism - with devastating consequences for the partnership. You need to have a clear sense of the benefits and a willingness to live with process pain and a level of risk in order to achieve the desired ends. All of this can be minimised through active management of the collaboration. There will always be a need to manage the complex balance between processes, substantive outcomes and recognition if commitment and energy are to be kept alive. Perhaps the likelihood of being able to have a story of successful partnership to recount depends on the expectations that you bring to the enterprise.

\section{ENDNOTES}

${ }^{1}$ Reproduced from The Partner 2007 by kind permission of Partnership Sourcing Ltd (PSL),

$<$ www.pslcbi.com $>$. This chapter is based on research carried out by the authors as part of a program of research on the management of collaboration undertaken within the ESRC/EPSRC Advanced Institute for Management Research. 